\title{
DIŞ BORÇLANMA KARŞISINDA NAMIK KEMAL VE ATATÜRK
}

\author{
Abdurrahman SİLER*
}

Bilindiği üzere, insan sosyal bir varlıktır. İnsanlar toplum halinde yaşarlar ve birbirlerine her konuda muhtaçtırlar. Maddî ihtiyaçların karşılanması için de, insanlar birbirleriyle ekonomik ve ticarî ilişkilere girmek zorundadırlar. Borç alıp verme de, bu gibi ihtiyaçlar arasındadır. Ancak borç alıp verme, kişiler arasında olduğu gibi, milletler veya devletler arasında da mümkündür, hatta bazan zarurîdir. İşte bu noktada "dış borç" problemi ile karşılaşıyoruz.

Osmanlı İmparatorluğu'nda ilk dış borç talebi, 1789 yılı sonlarinda olmuş, bunu 1799 ve 1839 sonlarındaki ikinci ve üçüncü talepler izlemiştir. İngilizler, kendilerinden istenen bu borçları, her üç seferinde de reddetmişlerdir. ${ }^{1}$

Osmanlı yönetimi, yabancı krediden yararlanma imkânını, ilk defa Kırım Savaşı (1853-1856) dolayısıyla bulmuştur. Ancak bu imkân istismar edilmiştir. Savaşlar, isyan masrafları, devamlı bütçe açıkları vb. harcamalar, hep bu görünüşte kolay ve külfetsiz yabancı istikrazlarla karşılanmıştır. İlerisi düşünülmeden hep "bugünii kurtarma" düşüncesine saplanılmış̧ır. Kırk elli sene içinde borçlar çı̆̆ gibi büyüyerek, sonunda devletin başına, kapitülâsyonlardan daha ağır ve siyasî bağımsızlı̆̆ı zaman zaman tehdit eden bir dert olmuştur. ${ }^{2}$

\section{Diş Borçlar Karşısında Namık Kemal}

Namık Kemal'in (1840-1888), hayatında hiç bir alanda derinleşme ve uzmanlaşma imkânı bulamadığı söylenebilir. Bu hüküm, ikti-

* K.T.Ư. Fatih Eğitim Fakültesi Sosyal Bilimler Eğitimi Bölümü Tarih Anabilim Dalı Araştırma Görevlisi.

1 Mübahat S. Kütükoğlu, Osmanl-1ngiliz Iktisâdi Münâsebetleri (1838-1850), C. II, İstanbul Úniversitesi Edebiyat Fakültesi yayını, İstanbu1, 1976, s. 111-112.

(2) Refii Şükrü Suvla, "Tanzimat Devrinde İstikrazlar", Tanzimat, (İstanbul, 1940), s. $263,275$. 
sadî konular için de geçerlidir. Fakat $\mathrm{O}$, belki de içinde yaşadığı şartların gereği olarak, çok çeşitli alanlarda kafa yormuş, kalem oynatmıştır. Daha çok bir "vatan şairi”" olarak bilinen Namık Kemal, edebî ve tarihî eserler yanında, "şaheser" denebilecek kalitede makaleler yazmıştır. Makalelerinin bir kısmı da ekonomik konularla ilgilidir. Osmanlı İmparatorluğu'nun ilk dış borçları hakkındaki yazıları ise, bu çalışmamızda söz konusu edilecektir.

Namık Kemal daha 1866 sonlarında, Tasvir-i Efkâr'da yazarken, istikrazlar konusu ile ilgilenerek, "Esham-1 Umûmiye"'3 hakkında yazdığ istikrazların yararlarının tartışmalı olduğunu ve ancak vatanın büyük bir tehlikeden kurtarılması gibi kesin zaruret hallerinde başvurulabilecek bir yol olarak kabul edildiğini belirtir. Bu makalesinde Namık Kemal, Osmanl Devleti'nde uygulanan birçeşit istikraz olan "Esham-1 Umûmiye"nin şartlarının, diğer istikraz çeşitlerine göre hafif ve ehven olduğunu öne sürerek, bu yolu tavsiye eder.

1868 yılında Osmanlı Devleti'nin sekiz milyon keseden fazla dış borçları ve bir o kadar da esham-1 umumiyesi ve "hesaba gelmez müteferrik borçları" bulunduğunu belirten Namık Kemal, dış borçlara başvurmanın sebepleri olarak savaşları, yapılan israfları ve hırsızlıkları gösterir. ${ }^{5}$

Dışarıya borçlanma meselesine dair fikirlerini daha çok Londra'da yayınlanan Hürriyet Gazetesi'nde yazmı̧ olan Namık Kemal, bu çeşit yazılarından bịrinde, özetle aşağıdaki görüşlere yer verir: ${ }^{6}$

Ekonomik gelişmenin asıl kaynağı üretimin ve gelirlerin arttırilmasıdır. Istikraz ise, iktisatçılara ve akıl sahiplerine göre, gerçek bir gelir kaynağı değil, ancak vatanı mutlak ve büyük bir tehlikeden kurtarma zarureti doğduğu an ve başka bir çare de bulunmadığı için başvurulabilecek bir "fedakârlıktır". Sosyal bilimcilerin çoğunluğuna göre, tarım, sanayi, ticaret gibi çalışma yoluyla gelir sağlamak varken,

3 Esham, Arapça asıllı bir kelime olup, "sehm”'in çoğuludur. Sehm, kısım, hisse; ok anlamlarına gelir. III. Mustafa zamanında çıkarılan istikraz kuponları için kullanılırdı. "Esham-1 Cedîde", "Esham-1 Mümtaze" adlarıyla da esham çıkarılmıştır. "Esham-1 Umûmiye" ise, iç istikraz kuponları hakkında kullanılan bir tabirdir (Daha fazla bilgi için bkz. M. Zeki Pakalın, Osmanlı Tarih Deyimleri ve Terimleri Sözlügüu, C. I, 2. baskı, Millî Eğitim Basımevi, İstanbul, 1971, s. 552.)

4 Bkz. Tasvir-i Efkâr, Sayı: 445, 13 Şaban 1283, s. 1.

5 Ayrıntılı bilgi için bkz. Hürriyet, Sayı: 7, 10 Ağustos 1868, s. 1.

6 Bkz. Hürriyet, Sayı: 10, 31 Ağustos 1868, s. 1-3. 
devletin araya girip de, çalışanlardan aldığı paraları, birtakım tembel sermayedârlara vermesinden daha büyük kötülük olamaz. Bu yol, "mirasyedi yetiştirme"nin çok kötü bir şeklidir.

İstıkraz taraftarları, Fransa örneğinde olduğu gibi, Avrupa devletlerinin de istikraz yaptıklarını öne sürerek, bu işı normal göstermeye çalı̧̧maktadırlar. Oysa Fransa, 1789'dan itibaren olağanüstü ölçüde büyük olaylarla ve savaşlarla karşılaşmıştır. Kaldı ki buna rağmen, Fransa'nın 1868 yılına kadarki borçları, yıllık gelirlerinin beş katı bile değildir. Borçlanına verdiği faiz \% 3'tür. Verdiği yıllık faiz toplamı, ylllık gelirinin yedide birine ulaşmaz. Osmanlı Devleti ise, Fransa gibi yüz yılda değil, 1854-1868 arasında aldığı borçlarının faizleri için, yıllık gelirinin üçte biri kadar faiz ödemekte ve istikrazlarını \% 6 faizle yapmaktadır. Üstelik Qsmanlı Devleti bu süre içinde Kırım Savaşı ile bazı küçük isyanlar dışında, çok büyük savaşlarla da karşılaşmiş değildir.

Osmanlı ekonomi ve maliyesinin kötüleşmeye başladığı zamanlardan beri izlenmesi gereken yol, bir yandan millî geliri artımaya çalışmak, bir yandan da acil olarak masrafları mümkün olan asgarî sınırlarına indirmek ve kesin zaruret olmadıkça "bir para borç almamak" idi.7 $\mathrm{Bu}$ ise, israfların ve hırsızlıkların önünü almakla yakından ilgili idi.

Tanzimatçılar iyi birer ekonomist veya maliyeci olmadıkları ${ }^{8}$ için, Namık Kemal'in aksine, dış borçlara iyice sarılmış bulunuyorlardı. Meselâ Fuat Paşa "bu devlet istikrazsız yaşamaz" diyordu. Bu söze canı sıkılan Namık Kemal, endişesini ve kanaatini şöyle belirtmiştir: "Hele bu gidişle hazinenin hali nereye varacağını bütün bütün tasavvurdan âciziz. Şurası iyi düşünülmelidir ki "devlet istikrazsız yaşamaz" değil, "yalnız istikraz ile yaşayamaz."9

7 R. Şükrü Suvla'ya göre (bkz. a.g.m., s. 285-288), bir devlet aldığı aıs borçları, ancak millı savunma ve üretim alanlarına yatırabilir. Tüketim alanlarına yatı̣ılırsa, bugünkü neslin sıradan ihtiyaçları, gelecek nesillere ödettirilmiş olur ki, bu durum en azından adaletsizliktir. Halbuki Osmanlı dış borçlarının 5/6'sı tüketim alanlarına, bütçe açıklarının kapatılmasına ve saray masraflarına harcanmıștır.

8 Stanford J. Shaw, Osmanl Imparatorluğu ve Modern Türkiye, C. II, Ceviren: Mehmet Harmanc1, e yayını, İstanbul, 1983, s. 197 .

9 Bkz. Hürriyet, Say1: 47'den naklen, Ithsan Sungu, "Tanzimat ve Yeni Osmanlılar", Tanzimat, (Istanbul, 1940), s. 834-835. Gerçekten Osmanlı yönetinii "devletin istikrarsız yaşayamayacağı" politikasını o kadar ileri götürmüștü ki, 1875'te 200.000.000 Ingiliz lirasına ulaşan dış borçların yıllık servisini ödemeyi başaramamıștı. Sonuçta çok geçmeden Osmanlı hükûmeti ile yabancı ve yerli alacaklılar arasında yapılan bir anlaşma ile, devletin gelirinin bir kısmı üzerinde Avrupa kontrolü kesin biçimde yerleşmiști. Düyûn-1 Umûmiye Idaresi böylece ortaya çıkmaya başlamıştır. (Niyazi Berkes, "Namık Kemal'in Fikrî Tekâmülü", Namık Kemal Hakkında, (İstanbul, 1942), s. 233-235.). 
Namık Kemal dış borçların, millî gelirde görülen gerilemenin ve hazinenin harap olmasının en önemli sebebi olduğunu belirttiği bir makalesinde. ${ }^{10}$ dış borçlar için şöyle bir bẹnzetme yapar: "İstikraz ile borç ödeyerek ıslâh-1 hale çalışmak, devr-i daim suretiyle makine yürütmeye uğraşmak kabilindendir". Aynı yazısında, İngiltere'nin \% 3 faizle para bulabildiğini, ama Osmanlı Devleti'nin, aldığı diş borçların en fazla \% 60'ını elde edebildiğini öne sürer. Nitekim yapılan araştırmalar Namık Kemal'i haklı çıkarmıştır. Meselâ Şükrü Baban'ın verdiği bilgiye göre ${ }^{11} 1858$ senesinde alınan beş milyon İngiliz lirası tutarındaki dış borcun, ancak üç buçuk milyon civarındaki bir miktarı elimize geçebilmiştir. Üstelik bu para da, "kaime"lerin12 iptal ve imhasına ayrılmıştır.

Tanzimatçıların, devletin malî itibarı sayesinde, Avrupalılardan kolaylıkla borç bulabildiklerini öne sürmeleri de Namık Kemal'i öfkelendirmiş görünüyor. "Muvazene-i Maliye" adlı makalesinde ${ }^{13}$ bu konuyu da ele alan Namık Kemal, dış borçların kolaylıkla bulunmasının, aslında devletin malî itibarı ile değil; devlete zararlı çok ağır şartların ${ }^{14}$ kabul edilmesi sayesinde gerçekleştiğini belirtir. "İki katına senet vererek fâhiş faizlerle" para alan Tanzimatçıların, borçları ödeyemez duruma düşünce, bu sefer borç ödemek amaciyla yeni borçlara yönelmelerinin, sonunda devleti bütünüyle iflasa sürükleyeceğini; bunoktadan itibaren de yabancı müdahalesinin kaçınılmaz olduğunu anlatmaya çalışır.

Namık Kemal, dış borçlar yüzünden, devletin malî hatta siyasî bağımsızlığının ortadan kalkabileceği hususundaki görüşünü, o zamanlar henüz Osmanlı Devleti'ne bağlı sayılan Tunus'un durumunu örnek göstererek ispatlamaya çalışmıştır. 24 Mayıs 1869'da yayınladığı

10 Bkz. "Muvazene-i Maliye", Hürriyet, Sayı: 62, 30 Ağustos 1869, s. 3.

11 Bkz. Şükrü Baban, "Tanzimat ve Para", Tanzimat, (1stanbul, 1940), s. 250.

12 "Kaime" ve bununla ilgili hususlar hakkında geniş bilgi için bkz. Mine Erol, Osmanlı Imparatorluğu'nda Kağıt Para (Kaime), TTK Basımevi, Ankara, 1970.

13 Bkz. Hürriyet, Say1: 62, 30 Ağustos 1869, s.2.

14 Gerçekten de Avrupalılar, Osmanlıların borç isteklerine karşılık çok ağır şartlar öne sürüyorlardı. Meselâ kaimelerin ortadan kaldırılmasına, halktan toplanan "mecburî iane'lerle, kendileri de Fransa'ya borçlu olan Baltazzi ve Zarifi gibi Galata bankerlerinden alınan borçlar da yetmeyince, 1860'larda hükûmet yine dış borç aramaya yönelmişti. Bu durumu öğrenen İngiliz elçisi, kendisine henüz resmî bir istek bile ulaşmamışken, Osmanlıya borç verme karşılığında şu küstahça şartları ileri sürmüştü: 1) Osmanlı parası Avrupa kontrolüne verilmelidir. 2) Yabancılar devlet mülklerini satın alma veya kiralama hakkını elde etmelidirler... (Bkz. Ş. Baban, a.g.m., s. 251). 
konu ile ilgili makalesinde, görüş ve endişelerini özetle şöyle dile getirir: ${ }^{15}$

Liyakatsiz ve yetersiz bazı devlet adamları yüzünden, Tunus'un zenginlikleri yok oluşa sürüklenmiştir. Ayrıca biz "Avrupa'nın dansını, şampanyasını taklit etmeye" başladığımız sıralarda, Tunus da istikraz belâsma uğradı. Âz zamanda 200.000.000 Frank'a yükselen dış borçlarına karşılık, Tunus'un sadece 15.000.000 Frank geliri vardır. Üstelik alınan bu borçlar da yerli yerinde sarfedilmeyip israf edilince durum daha da vahimleşti. Öyle ki, Tunus'un borçlarının faizleri bile ödenemez oldu. Böylece Tunus'a Avrupa'nın müdahale firsatı doğmuş bulunmaktadır. Fransa'nın Tunus'a tek başına müdahalesi "istilâ rengini alacağından" birlikte müdahaleyi menfaatlerine - uygun gören diğer devletlerin katılmasıyla, ortak bir Avrupa müdahalesi söz konusudur. Ortak bir komisyon bir kere Tunus'a girer ve bu ülke yıllarca Avrupalıların çiftlikleri gibi kullanılırsa, bize artık Tunus'tan hayır gelmez. Avrupa böyle bir metotla Tunus'u Osmanlılardan koparırsa ${ }^{16}$ bu örneğe bakarak Misır ${ }^{17}$ hatta İstanbul bile, böyle dolaylı yollarla elimizden alınmaya çalışılacaktır. Zaten 1856'dan itibaren halkın ağzında "nihayet hazinemizin idaresini Avrupalılar ele alarak, devlet o suretle mahvolacak" gibi sözler duyulmaya başlamıştır. Ne yazık ki bu endişe gerçekleşecek gibidir. Çünkü faiz ödeme amacıyla borç alma zaruretine düşürüldük. Bu yolda gidilirse, Osmanlı Devleti toptan Tunus'un durumuna düşebilir. Osmanlı hazinesi "sarrafların faiz merkebi"nden daha kötü bir durumdadır. Tunus'ta olduğu gibi, İstanbul'a da ortak bir Avrupalı komisyon gelebilir. Bu durumda halk, bütün Avrupa ile savaşamıyacağına göre, millî egemenliğine bedel, Avrupa'nın vesayeti altına girme zilletini kabul edecektir. ${ }^{18}$

15 Bkz. Nam.k Kemal, "İbret", Hürriyet, Sayı: 48, 24 Mayıs 1869, s. 2-3.

16 Nitekim Namık Kemal'in bu yazısının yayınlanmasından sadece 12 yıl sonra Tunus, 1881'de Fransa'nın eline geçmiștir. S.J. Shaw'a göre (bkz. a.g.e., C. II, s. 241), Tunus Beyi'nin ekonomik sıkıntıiarı ve dış borçlanı, Tunus'a Avrupa müdahalesini davet etmişti. Bu müdahale gerçekten de daha sonra Mısır ve İstanbul için de geçerli olmuştur. minștur.

17 Mısır'ın da 1882 'de Ingilizler tarafından işgali, Namık Kemal'i yine haklı şıar-

18 Osmanlıların kendi idaresizlikleri ile birlikte, vadesi gelen çok büyük dı̧ borçiar yüzünden, yabancıların malî müdahalesi kaçınılmaz duruma gelmişti. (S.J. Shaw, a.g.e., C. II, s. 198). Avrupa'da sermaye çoktu, istenildiği zaman veriyordu. 1854-1875 yılları arasında Osmanlıların đıș borçlarının miktarı, bir milyon doları geçmişti. Bu durumda 1879'da İngiliz Dışişleri Bakanı Lord Derby'nin dediği gibi, Osmanlı Devleti’nin içişlerinde karşılaştığı devamlı murakabe, ülkenin bağımsızhı̆ını sıfıra indirmiștir (N. Berkes, a.g.m., s. 234235) 


\section{Diş Borç Problemi ve Atatürk}

Namık Kemal'in, gelişigüzel dış borçlanmanın tehlikeli sonuçları hakkındaki endişeleri bir bir gerçekleşir ve Osmanlı İmparatorluğu yıkılışa doğru yol alırken, Mustafa Kemal Atatürk de çocukluk, gençlik ve olgunluk çağlarını yaşıyordu (1881-1918). Atatürk'ün, Namık Kemal'in şiir, makale ve eserlerini öğrencilik yıllarından itibaren okumaya başladığı, O’nun fikirlerinden büyük ölçüde etkilendiği, yapilan bazı çalı̧̧malarla ortaya konmuş bulunmaktadır ${ }^{19}$. Osmanlı İmparatorluğu'nun çöküşünde ve dağılmasında, ağır dış borç yükünün önemli bir rol oynadığını çok iyi kavramış olan Atatürk, bu konuda elbette Tanzimat dönemi yöneticileri gibi değil, onları şiddetle eleştirmiş olan Namık Kemal gibi düşünüyordu. Ancak Atatürk, Namık Kemal'den farklı olarak, sadece düşünmekle kalmamış, fikirlerini uygulama alanına koymayı da başarmıştır. Çünkü $O$, yepyeni bir devletin kurucusu olmuş ve on beş yll Türkiye'nin ilk Cumhurbaşkanlığını yapmiştır.

Gazi Mustafa Kemal Atatürk, daha Millî Mücadele devam ederken, 1 Mart 1922'de, Büyük Millet Meclisi'nin üçüncü toplantı yılını açı§̧ konuşmasında, tam bağımsızlı̆ıı ekonomik bağımsızlikla ilişkisi, dıs borçlanmanin şartlanı, dışticaret dengesi ve tasarruf gibi hususlarda şunları söylüyordu:20

"Efendiler! Bugünkü mücahedatımızın gayesi istiklâl-i tamdır. İstiklâliyetin tamamiyeti ise ancak istiklâl-i malî ile mümkündür.

Bir devletin maliyesi istiklâden mahrum olunca o devletin bütün şuabat-1 hayatiyesinde istiklâl meflûçtur. Çünkü her uzv-u devlet ancak kuvvet-i maliye ile yaşar. İstiklâl-i malînin mahfuziyeti için şart-1 evvel, bütçenin bünye-i iktisadiye ile mütenasip ve mütevazin olmasıdır. Binaenaleyh; bünye-i devleti yaşatmak için harice müracaat etmeksizin memleketin menabii varidatiyle temini idare çare ve tedbirlerini bulmak lâzım ve mümkündür.

19 Namık Kemal'in Atatürk'e etkisi ve bu konu ile ilgili husıslar hakkında bilgi için bkz. Şerafattin Turan, Atatürk'ün Düşünce Yapıstnı Etkileyen Olaylar, Düşünürler, Kitaplar, T.T.K. yayını, Ankara, 1982; Yahya Akyüz, "Atatürk'te Namı Kemal'in Etkisi ve Abdülhamit Döneminde Yasak Kitaplara Ilişkin İki Belge”, Belleten, C. XLV/2, Ekim 1981, Say1: 180'den ayribasım, T.T.K. Basımevi, Ankara, 1981.

20 Bkz. Atatürk'ün Söylev ve Demegleri, C.I., (1919-1938), Türk Inkılâp Tarihi Enstitüsü yayını, İstanbul, 1945, s. 222-223. 
"Efendiler! Âzami tasarruf şiarı millîmiz olmalıdır.

"Binaenaleyh; usulü malîmiz, halkı tazyik ve izrar etmekten içtinab ile beraber mümkün olduğu kadar harice arz-1 ihtiyaç ve iftikâr etmeden varidat-1 kâfiye temin etmek esasına müstenittir. Şimdiki halde istifade edilemiyen menabii varidattan müstefit olmak ve halkın bâr-1 tekâlifini tahfif etmek için bazı mevat üzerinde inhisarlar vaz'eylemek lâzimedendir.

"Efendiler! Mazinin ve düşmanların memleket ve milletimizi bütün dünya-yı medeniyetle birlikte terakkiye yürütmekten menetmiş olan zencirleri, bugün bizi, az zamanda fevkalâde teşebbüsat ve icraatta bulunmıya icbar ediyor. Ancak bu mecburiyetin tatmini ve zayiatın telâfisi bugünkü kudret-i maliyemizin fevkındadır. Bundan dolayı hükûmetimizin her medenî devlet gibi haricî istikrazlar akdetmesine lüzum vardır. Şu kảdar ki istikraz olunan ecnebi paralarını, şimdiye kadar Babıâli'nin yaptığı tarzda, ödemiye mecbur değilmişiz gibi, maksatsız israf ve istihlâk ile bâr-1 düyûnumuzu artırarak istiklâl-i malîmizi mâruz-1 tehlike etmeye katiyen muarızız. Biz memlekette, mamuriyeti, istihsali ve refah-1 halkı temin edecek, menabi-i varidatımızı inkişaf ettirecek müsmir istikrazlara taraftarız."

Atatürk, Millî Mücadele'nin zaferle sonuçlanmasından birkaç ay sonra, Izmir'de toplanacak Birinci İktisat Kongresi'ne az bir süre kala, gazetecilere verdiği bir demeçte, yeni Türkiye'nin "cihangir bir devlet" değil, "bir devlet-i iktisâdiye" olacağını belirtiyor ve yabancı sermaye hakkında da şöyle diyordu :21

“...Filhakika memleketimizi az bir azamanda ma'mûr etmek için milletimizin gayr-i kâfi sermayesi karşısında hârici sermayesinden, vesâitinden, ihtisâsından istifade etmek hakikî menfaatimiz iktizâsındandır. Hükûmetimiz, izahına lüzum olmayan esâsâtın riâyetkârı kalacak olan her devlet ve millete karşı bu hususta emniyet ve samimiyetle ahz-1 mevki' edecektir."

21 Bkz. Tanin, 20 Kânunusaâni 1339/1923, (2 Cemaziyelâhir 1341), s. 2. 
Atatürk, 17 Şubat 1923 günü başlayan Birinci İzmir İktisat Kongresi'nin açı̧ nutkunda ise, yeni Türkiye'yi lâyık olduğu gelişme derecesine ulaştırmak için, ekonomimize mutlaka birinci sırada önem vermek gerektiğini, zamanımızın bir "iktisat devri" olduğunu belirtiyor ve tam bağımsızlıkla ekonomik güç arasındaki ilişkiyi şu sözlerle ortaya koyuyordu:22

"İstiklâl-i tam için... yegâne kuvvet, hakikî en kuvvetli temel iktisadiyattır.

"Siyasî, askerî muzafferiyetler nekadar büyük olursa olsunlar, iktisadî muzafferiyetler ile tetviç edilemezlerse husule gelen zaferler pâyidar olamaz, az zamanda söner..."

Yabancı sermayeye bazı şartlarla karşı olmadığını anlatırken. Atatürk, Tanzimat devri anlayışını şiddetle eleştiriyordu:23

“...Efendiler, iktisadiyat sahasında düşünürken ve konuşurken zannolunmasın ki, biz ecnebî sermayesine hasım bulunuyoruz. Hayır, bizim memleketimiz vâsidir. Çok sa'y ve sermayeye ihtiyacımız vardır. Binaenaleyh kanunlarımıza riayetkâr olmak şartıyla ecnebi sermayelerine lâzım gelen teminatı vermeye her zaman hazırız ve şâyân-1 arzudur ki, ecnebi sermayesi bizim sa'yimize ve servet-i sâbitemize inzimam etsin. Bizim için ve onlar için faydalı neticeler versin; fakat eskisi gibi değil. Filhakika mazide ve bilhassa Tanzimat devrinden sonra, ecnebi sermayesi memlekette müstesna bir mevkie malik oldu. Ve ilmî mânâsıyla denebilir ki, devlet ve hükûmet écnebi sermayesinin jandarmalığından başka bir şey yapmamıştır. Artık her medenî devlet gibi, millet gibi, yeni Türkiye dahi buna muvafakat edemez. Burasını esir ülkesi yaptıramaz."

Yukarıda sözü edilen açış nutkunda, ülkemizin bir tarım ülkesi olması dolayısıyla tarıma büyük bir önem verilmesi gerektiğini, ancak sanayii de "tezyid ve tevsi etmek mecburiyetinde" olduğumuzu belırten Atatürk, sanayi hususunda gevşek davranılması halinde, endüstri ürünlerinde yine yabancı ülkelerin "haraçgüzarı" olma tehli-

22 Bkz. Atatürk'ün Söylev ve Demeģleri, C. II, (1906-1938), 2. baskı, Türk İnkılâp Tarihi Enstitüsü yayını, Ankara, 1959, s. 100, 107.

23 Bkz. Atatürk Devri Fikir Hayat, C. I, Hazırlayanlar: Mehmet Kaplan-İnci Enginün-Zeynep Kerman-Necat Birinci-Abdullah Uçman, Kültür Bakanlığı yayıni, Ankara, 1981 , s. $315-316$. 
kesinin doğacağını; üretimimizin paraya çevrilebilmesi için ise, yabancı elinde olan ticaretimizin, kendi elimize geçmesi gerektiğini söylüyordu. ${ }^{24}$

Atatürk, Birinci İktisat Kongresi'nin 4 Mart 1923'te sona ermesinden on iki gün sonra Adana'da çiftçilere yaptığı bir konuşmasında, ekonomik bağımsızlığın ne kadar önemli olduğunu tekrar gündeme getirerek şöyle diyordu:25

“...Adana senevî 35 milyonu yalnıź pamukla pekâla temin edebilir. Biz bunların inşaallah hepsini temin edeceğiz. Yalnız bunun için bir şeye ihtiyaç vardır: İktisadiyatımızda istiklâli tam. Güzel vatanımızı fakre, memleketi harabiye sürükliyen esbabı muhtelife içinde en kuvvetli ve en ehemmiyetlisi iktisadiyatımızda istiklâlden mahrumiyetimizdir..."

Atatürk'ün, dı̧ borçlara girilmesine ve yabancı sermayeden yararlanmaya prensip olarak olumlu baktığı, demeç ve konuşmalarından açıkça anlaşılmaktadır. Ancak O'na göre, dış borçlar ve yabancı sermaye, Türkiye'nin tam bağımsızlığını zedelememeli ve millî egemenlik esasına zarar vermemelidir. Bu şarttan kesinlikle vazgeçilemez. ${ }^{26}$

\section{SONUÇ}

Atatürk'ün dış borçlanma ve bununla ilgili hususlarda ortaya koyduğu görüşler, Namık Kemal'in bu konudaki fikirleriyle büyük ölçüde benzerlik arzetmektedir. Sözü uzatmamak için, Atatürk ün dış borçlarla ilgili olarak, Cumhurbaşkanlığı dönemindeki uygulamalarına girmemek yerinde olur. Burada şu kadarı belirtilmelidir ki, Atatürk bu dönemde, en yakın arkadaşlarının bütün tavsiye ve ısrarlarına rağmen, yabancı ülkelerden borç almamaya özen göstermiștir.

Namık Kemal ile Atatürk'ün dış borç problemi hakkındaki ortak görüşleri şöyle özetlenebilir:

1) Diş borçlanma prensip olarak mümkündür. Ancak bu konuda devletin malî ve ekonomik bağımsızlığının zarar görmemesi esastır.

24 Bkz A.g.e., C. I, s. 318-319.

25 Bkz. Atatürk'ün Sộlev ve Demę̧leri, C. II (1906-1938), Ankara, 1959, s. 119.

26 Cihan Duru-Kemal Turan-Abdurrahman Öngeoǧlu, Atatürk Dönemi Maliye Politikası, Ankara, 1982, s. 407. 
2) Bu esasa dikkat edilmez ve gelişigüzel bir şekilde, millet menfaatleri göz önüne alınmadan dış borçlanmaya gidilirse, çok geçmeden siyasî bağımsızlık da tehlikeye girer. Örnek olarak, Osmanlı İmparatorluğu'nun yıkılışında dış borçlarının rolünün bilinmesi yeterlidir.

3) Devlet yönetiminde lüks, israf, yolsuzluk vb. gibi olumsuzluklar önlenirse, yabancı ülkelerden fazla borç para almaya gerek kalmaz. Asıl olan, ülke kaynakların en verimli bir şekilde değerlendirmek ve çok çalışarak bol üretim sağlamaktır.

Namık Kemal'in ve özellikle Mustafa Kemal Atatürk'ün, dış borçlanmaya niçin sıcak bakmadıkları konusu, günümüz Türkiye'sinde yeteri kadar anlaşılmıs mıdır? Bu sorunun cevabı ise, ayrı bir araştırmanın konusu olabilir. 